Annals of International Medical and Dental Research

E-ISSN: 2395-2822 | P-ISSN: 2395-2814

Vol-8, Issue-1 | January-February 2022

DOI: $10.53339 /$ aimdr.2022.8.1.20

Page no- 149-158 | Section- Research Article (Paediatric Surgery)

\title{
Preoperative Factors Affecting the Outcome of Single Stage Hypospadias Repair- An Observational Study
}

\author{
Narinder Singh ${ }^{1}$, Ab. Hamid Wani2* ${ }^{*}$ Tippu Ishar ${ }^{3}$, Deepak Kumar ${ }^{4}$, Nasib Chand Digra ${ }^{5}$
}

\begin{abstract}
${ }^{1}$ Associate Professor, Deprtment of Paediatric Surgery, Government Medical College Jammu, Jammu and Kashmir, India.

Email: nsingh321@rediffmail.com

Orcid ID: 0000-0001-6528-1286

2Assistant Professor, Department of Surgery, Government Medical College Jammu,Jammu and Kashmir, India.

Email: drhamid121@gmail.com

Orcid ID: 0000-0002-4415-2706

3Consultant, Deprtment of Pathologist, Department of Pathology Government Medical College Jammu, Jammu and Kashmir, India.

Email: isher123@gmail.com

Orcid ID: 0000-0003-3085-8764

4Senior Resident, Department of Surgery, Government Medical College jammu, Jammu and Kashmir, India.

Email: deepakbhagat543@gmail.com

Orcid ID: 0000-0001-5500-6264

5 Professor and Head, Department of Surgery, Government Medical College jammu, Jammu and Kashmir, India. Email: ncdigra4@gmail.com Orcid ID: 0000-0002-9597-9172
\end{abstract}

${ }^{*}$ Corresponding author

Received: 19 September 2021

Revised: 23 November 2021

Accepted: 04 December 2021

Published: 22 December 2021

\begin{abstract}
Background: Hypospadias is one of the commonest congenital anomaly in boys which requires either a single stage repair or staged repair. The success of the procedure depend upon the type, anatomy, experience of the surgeon, method of repair and preoperative hormonal stimulation. Aim: The aim of the study was to evaluate the various preoperative factors responsible for outcome of single stage repair in distal penile, mid penile and proximal penile hypospadias.

Methods: There were 48 patients in this observational study which were divided into two groups. Group A comprised of 24 patients with glanular and coronal hypospadias while Group B comprised of 16 patients with distal penile, 5 mid penile and 3 proximal penile types with minimal chordae. All the $24(50 \%)$ patients in group A underwent meatal advancement and glanuloplasty incorporated (MAGPI) repair while in group B $15(31.25 \%)$ patients underwent Tabularized Incised Plate (TIP) repair and 9 (18.75\%) patients underwent combined TIP and Mathieu's repair. Results: Overall operative success rate observed in the study was 41 (85.41\%) patients. In $7(14.58 \%)$ patients urethrocutaneous fistula as a major complication occurred which included 1 patient in Group A and 2 patients with Distal Penile Hypospadias (DPH), 2 patients with Mid Penile Hypospadias (MPH) and 2 patients with Proximal Penile Hypospadias (PPH) in Group B. In $2(4.16 \%)$ patients, mild meatal stenosis was noted which settled with meatal dilatation. Urethrocutaneous fistula (UCF) disappeared in $2(4.16 \%)$ patients on follow up with regular urethral dilatation. Conclusion: MAGPI is the ideal procedure for glanular/coronal hypospadias. For distal penile hypospadias, TIP alone or combined TIP and Mathieu's repair gives equally good results. Preoperative testosterone therapy reduces the incidence of complications in a single stage hypospadias repair.
\end{abstract}

Keywords:- Distal penile hypospadias(DPH), Meatal advancement and glanuloplasty incorporated (MAGPI), Tubularised incised plate urethroplasty (TIP), Mathieu's repair, Urethrocutaneous fistula (UCF).

\section{INTRODUCTION}

Hypospadias is a common congenital anomaly with an incidence of $0.4-8.2$ per 1000 live births and is the second most common congenital disorder after cryptorchidism in boys. ${ }^{[1,2]}$ It has been classified into three types- Anterior or distal (glanular,coronal and subcoronal), 
Annals of International Medical and Dental Research

E-ISSN: 2395-2822 | P-ISSN: 2395-2814

Vol-8, Issue-1 | January-February 2022

DOI: $10.53339 /$ aimdr.2022.8.1.20

Page no- 149-158 | Section- Research Article (Paediatric Surgery)

middle (midpenile and proximal penile) and posterior or proximal (penoscrotal, scrotal and perineal). Anterior type constitutes the majority $65-70 \%$ of the cases, with mid type constituting $10-15 \%$ and posterior 20\%.[3] Principles of repair involve straightening of penis (Orthoplasty), creating a slit like opening at the tip of penis (Urethroplasty and Meatoplasty), making the glans conical looking (Glanuloplasty) and proper skin coverage.[4] The surgery can be done in a single stage (distal penile,midpenile and proximal penile types without significant chordae) or staged repair (proximal penile, penoscrotal, scrotal, perineal with significant chordae.[5] Different preoperative factors and methods of repair in a single stage procedure have been evaluated from time to time in literature to reduce the complication rate. The major complications in hypospadias repair are; urethrocutaneous fistula, urethral stricture, urethral diverticulum, meatal stenosis, wound infection, impaired healing and breakdown of repair. A number of procedures like MAGPI, Mathieu repair, Horton-Devine procedure, Mustarde repair, Onlay procedure, Snodgross procedure, Combined Mathieu's and Snodgross repair have been described for anterior hypospadias. $[6,7,8]$ But the quest for single stage operative procedure with excellent results and minimal complications is still continuing. [9] The choice of hypospadias repair varies depending upon the size of the phallus, characteristics of urethral plate, position of meatus, presence of chordae and experience of the surgeon.[10] Different studies and reports have been published in literature to evaluate factors which influence the outcome of repair in hypospadias like age of the patient, size of phallus, glans shape, urethral plate width, prepucial vascularity and preoperative androgen stimulation to increase the vascularity and size of the phallus. $[11,12,13,14,15,16]$ The present study was undertaken to evaluate the suitability of different procedures and effect of various preoperative factors like age of the patient, size of phallus, androgen stimulation and urethral plate anatomy in patients who underwent single stage hypospadias repair.

\section{MATERIAL AND METHODS}

Forty eight 48 patients were included in this study with hypospadias who required a single stage repair in the Postgraduate Department of Surgery, Government Medical College Jammu over a period of 1 year between November 2018 to October 2019. Ethical clearance was taken from ethical committee of the institute. All the patients were evaluated preoperatively which included history, systemic examination, examination to rule out associated anomalies and detailed local examination of hypospadias and external genitalia. In local examination morbid anatomy was assessed regarding the size of phallus, shape of glans, location of the external urethral meatus, urethral plate width, presence or absence of chordee, degree of chordae and prepuce status. Size of phallus was assessed on visual appearance for the operative procedure and patients were divided as having adequate or inadequate length. In those patients where penile length was inadequate, preoperative testosterone therapy was given in a dose of $2 \mathrm{mg} / \mathrm{kg}$ body weight on weekly basis for three weeks. Urethral plate characteristics which included width of the urethral plate more than $8 \mathrm{~mm}$ or less than $8 \mathrm{~mm}$ was assessed by using Vernier Calliper. 
Annals of International Medical and Dental Research

E-ISSN: 2395-2822 | P-ISSN: 2395-2814

Vol-8, Issue-1 | January-February 2022

DOI: $10.53339 /$ aimdr.2022.8.1.20

Page no- 149-158 | Section- Research Article (Paediatric Surgery)

\section{Inclusion criteria}

- All children upto 18 years

- Patients who needed single stage repair

- Minimal chordae

\section{Exclusion criteria}

- Patients with penoscrotal, scrotal Hypospadias

- Severe chordae

- Patients who needed redo surgery

All relevant preoperative investigations including complete blood count, coagulation profile, serology, urine examination and ultrasound of abdomen if needed were done. An informed consent was taken from parents/ guardian before surgery. For the purpose of operative intervention, patients were divided into two groups; Group A having glanular and coronal type $24(50 \%)$ patients and Group B having distal penile $16(33.33 \%)$, mid penile 5 $(10.41 \%)$ and proximal penile $3(6.25 \%)$ patients. All the patients were operated in elective operation theatre under General Anesthesia with caudal block and antibiotic prophylaxis (Inj. Ceftriaxone and Inj. Amikacin) at the time of induction.Group A patients underwent MAGPI urethroplasty as per standardized technique. A silk stay suture was placed on glans and meatal advancement was done by giving a vertical incision in the urethral plate and stiching it transversaly by 5-0 vicryl sutures. A subcoronal incision was made proximal to native meatus extending all around the coronal sulcus. Glans wings were mobilized from the side of corpus and glanuloplasty was accompalished by elevating the ventral side of meatus forwards and rotating the glanular wings upwards and ventrally in a conical manner. Reapproximation of the glans was done in two layers using 5-0 vicryl sutures. Feeding tube was placed into bladder for the drainage of urine and pressure dressing applied. Dressing was changed after 48 hours of surgery and catheter was removed after 72 hours of operation. Patient was discharged on oral antibiotics with advice to follow up in Surgery OPD as per the protocol.Group B patients underwent either TIP Urethroplasty with urethral plate width of more than $8 \mathrm{~mm}$ or Combined repair (TIP and Mathieu's) with urethral plate width of less than $8 \mathrm{~mm}$. In TIP urethroplasty [Figure 1], after placing a stay suture on the glans, feeding tube was placed into the bladder. $A^{\prime} U^{\prime}$ shaped incision was made along the lateral margins of urethral plate. Penis was degloved and glans wings were dissected out. A relaxing incision was made in midline of urethral plate and tension free tubularization of the urethra was done using 5-0 PDS continuous suture. Neourethra was covered by dartos flap created out of inner preputial layer and rotated ventrally with interrupted 5-0 vicryl sutures. Glanuloplasty was done in two layers followed by skin coverage of penile shaft. Pressure dressing was applied. In Combined repair after placing the stay suture [Figure 2], a feeding tube of appropriate size was introduced into the bladder. A meatal based Mathieu's flap was marked equal in length to urethral plate and mobilized. A parallel incision was made along the lateral margin of urethral plate. Penis was degloved and glans wings raised. A midline incision was made in the native urethral plate and neourethra was created by suturing the 
Annals of International Medical and Dental Research

E-ISSN: 2395-2822 | P-ISSN: 2395-2814

Vol-8, Issue-1 | January-February 2022

DOI: $10.53339 /$ aimdr.2022.8.1.20

Page no- 149-158 | Section- Research Article (Paediatric Surgery)

Mathieu's flap with lateral margin of urethral plate with continuous 5-0 PDS suture. Repair was covered by dartos flap dissected from the inner prepuce layer and rotated ventrally. Repair was completed after glanuloplasty and skin coverage of penis. Pressure dressing was applied over sofra tulle.In Group B pateints, first dressing was changed after 96 hours of the operative repair after which wound was kept open and Neosporin Ointment was applied over the suture line. Patients were discharged after change of first dressing on oral antibiotics, analgesics, laxatives and anticholinergics. In the immediate postoperative period any complications like bleeding, wound infections, seroma formation, haematoma formation, skin necrosis and catheter related problems were recorded. Feeding tube was removed after 10-12 days in the OPD and patients were advised to come for follow up after 1 week of the catheter removal. Patients were followed up in the OPD for urethral calibration and dilatation weekly for 1 month, twice weekly for 3 months and subsequently if required. After catheter removal and in follow up complications like urethrocutaneous fistula, meatal stenosis, urethral stricture were noted.

\section{RESULTS}

A total of 48 patients were enrolled in the study. Age of the patients varied between 2-18 years with majority of $34(70.83 \%)$ patients below 7 years of age, 10 (20.83\%) between 8-13 years and only $4(8.33 \%)$ above 14 years. In 8 $(16.6 \%)$ patients belonging to Group B minimal skin chordae was present. In $26(54.16 \%$ ) patients (14 belonging to group A and 12 belonging to group B), preoperative testosterone therapy was given after clinical assessment of the phallus size as shown in [Table 1]. All the $24(50 \%)$ patients in group A underwent MAGPI repair while in group B depending upon the urethral plate width and type of anomaly TIP urethroplasty alone or combined with Mathieu's repair was done as shown in [Table 1]. TIP urethroplasty was done in $15(31.25 \%)$ patients which included distal penile hypospadias with urethral width of $>$ $8 \mathrm{~mm}$, midpenile and proximal penile type of hypospadias. In $9(18.75 \%)$ patients of $\mathrm{DPH}$ with a urethral width $<8 \mathrm{~mm}$ combined TIP and Mathieu repair was performed. Major complication noted in the study was UCF in 7 $(14.58 \%)$ patients ( 1 in group A and 6 in group B) . The incidence of fistula formation was more in patients having age $>10$ years with an incidence of $2(28.57 \%)$ as compared to 5 $(12.19 \%)$ patients with $<10$ years of age. Also observed in the study was more incidence of UCF in $5(22.72 \%)$ patients where preoperative testosterone was not given as compared to $2(8.33 \%)$ patients where it was given as shown in [Table 1]. Another observation made in the study was disappearance of UCF in 2 (one group A and 1 group B with combined repair) in the follow up period with urethral calibration there by lowering the overall fistula incidence to $5(10.41 \%)$ in the study. The other complication noted in the present study was mild meatal stenosis in 2 patients of group B which settled in the follow up period with regular meatal calibration and superficial skin necrosis in 1 patient of group B without any subsequent effect on the repair. 
Annals of International Medical and Dental Research E-ISSN: 2395-2822 | P-ISSN: 2395-2814 Vol-8, Issue-1 | January-February 2022 DOI: 10.53339 /aimdr.2022.8.1.20 Page no- 149-158 | Section- Research Article (Paediatric Surgery)

Table 1: Showing the incidence of UCF in relation to various factors

\begin{tabular}{|c|c|c|c|}
\hline & \multicolumn{3}{|l|}{ Urethrocutaneous Fistula } \\
\hline Parameters & Groups & Yes & No \\
\hline \multirow[t]{3}{*}{ Type of repair } & $\begin{array}{l}\text { Group A }(24) \\
\text { MAGPI repair }\end{array}$ & $1(4.16 \%)$ & $23(95.83 \%)$ \\
\hline & $\begin{array}{l}\text { Group B (24) TIP repair } \\
\text { Distal penile }(7) \\
\text { Mid penile }(5) \\
\text { Proximal penile }(3) \\
\text { TIP with Mathieu's repair } \\
\text { Distal penile }(9)\end{array}$ & $\begin{array}{l}1(14.28 \%) \\
2(40 \%) \\
2(66.66 \%) \\
1(11.11 \%)\end{array}$ & $\begin{array}{l}6(85.71 \%) \\
3(60 \%) \\
1(33.33 \%) \\
8(88.88 \%)\end{array}$ \\
\hline & Total & $7(14.58 \%)$ & $41(85.42 \%)$ \\
\hline \multirow[t]{2}{*}{ Age } & $>10$ yrs $(7)$ & $2(28.57 \%)$ & $5(71.43 \%)$ \\
\hline & $<10$ yrs $(41)$ & $5(12.19 \%)$ & $36(87.81 \%)$ \\
\hline $\begin{array}{l}\text { Preoperative } \\
\text { testosterone }\end{array}$ & $\begin{array}{l}\text { Not given (22) } \\
\text { Given (26) }\end{array}$ & $\begin{array}{l}5(22.72 \%) \\
2(8.33 \%) \\
\end{array}$ & $\begin{array}{l}17(77.28 \%) \\
24(91.67 \%) \\
\end{array}$ \\
\hline
\end{tabular}

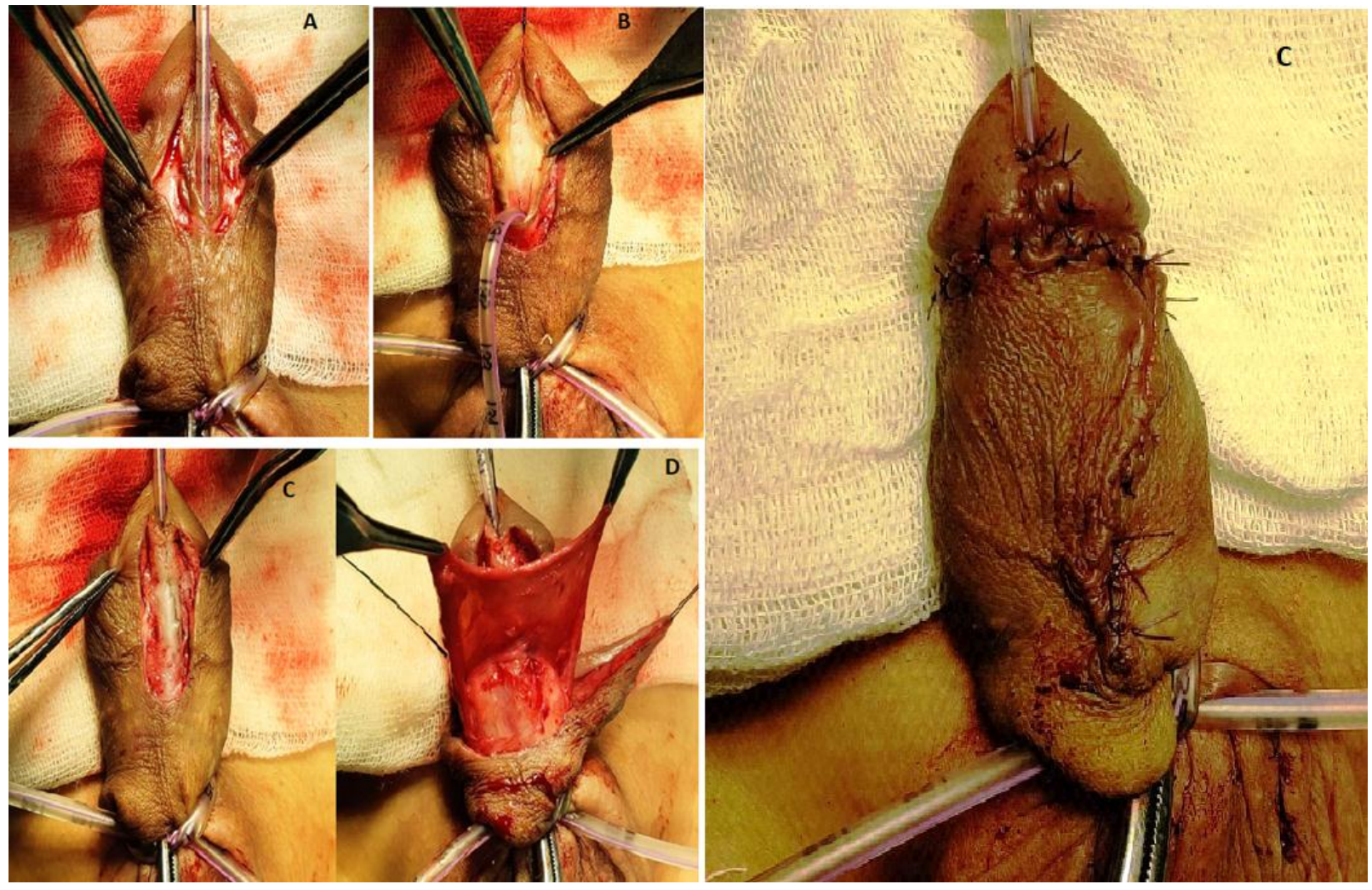

Figure- 1 
Annals of International Medical and Dental Research E-ISSN: 2395-2822 | P-ISSN: 2395-2814

Vol-8, Issue-1 | January-February 2022 DOI: 10.53339/aimdr.2022.8.1.20

Page no- 149-158 | Section- Research Article (Paediatric Surgery)
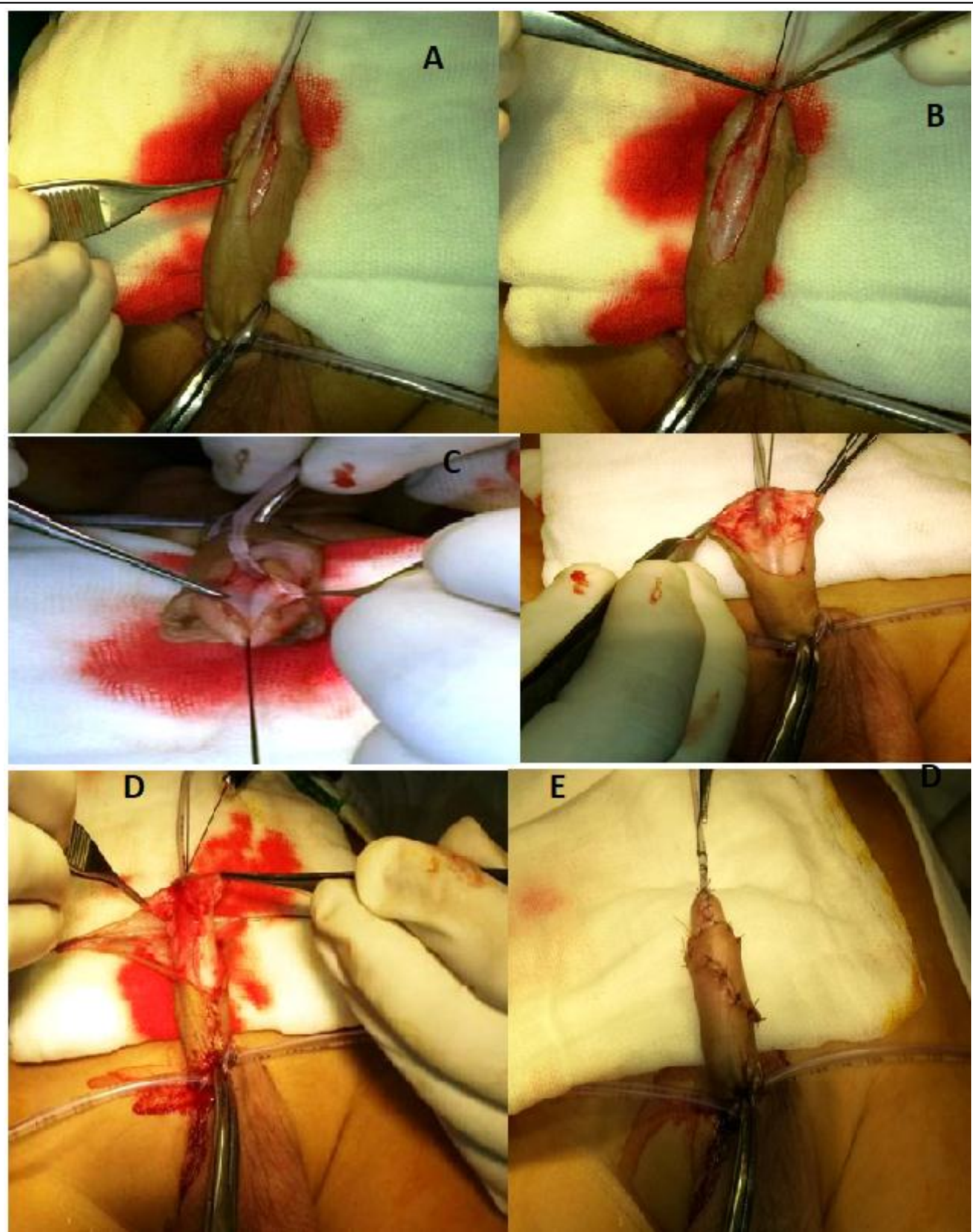

Figure- 2 
Annals of International Medical and Dental Research

E-ISSN: 2395-2822 | P-ISSN: 2395-2814

Vol-8, Issue-1 | January-February 2022

DOI: $10.53339 /$ aimdr.2022.8.1.20

Page no- 149-158 | Section- Research Article (Paediatric Surgery)

\section{DISCUSSION}

Surgery for Hypospadias has remained a challenge for the treating Surgeons as the complications rates are high in the inexperienced hands and learning curve is long. Over the past century surgical treatment continued to develop and not a single preferred technique could be advised for different types of hypospadias.[10] Anterior hypospadias is generally managed by one stage procedure with most popular techniques like MAGPI, Snodgrass (TIP) procedure, Mathieu's technique and Onlay procedure.[6,7] For glanular and coronal hypospadias, different procedures have been reported in literature like MAGPI, TIP procedure, Urethral Advancement procedure and $\mathrm{M}$ inverted $\mathrm{V}$ Glanuloplasty.[5] In the present study we performed MAGPI repair in all 24 patients with a diagnosis of glanular and coronal hypospadias and our results were excellent with fistula formation in only $1(4.16 \%)$ patient. J. Duckett et al., and MA Abdelrahman et al also recommended that MAGPI as an excellent procedure for glanular and coronal hypospadias in their study.[17,18] TIP urethroplasty has become the most popular technique for distal hypospadias repair worldwide since its introduction in 1994,[19,20] and with experience its application has also been extended to mid penile and proximal penile types. $[5,21]$ The major complication with this procedure in the beginning has been urethrocutaneous fistula, which with consecutive modifications particularly covering the repair with dartos layer from inner prepuce has been brought down to $5.7 \%$.[22] In the present study TIP urethroplasty was performed in 15 patients (7 patients of
$\mathrm{DPH}, 5$ patients of $\mathrm{MPH}$ and 3 patients of $\mathrm{PPH}$ ) with urethrocutaneous fistula formation in only $1(14.28 \%)$ patient with distal penile hypospadias and 4 (50\%) patients with mid penile and proximal penile hypospadias. Our results in distal penile hypospadias are comparable with the other studies but a higher fistula rate seen in mid penile and proximal penile type may be attributed to the morbid anatomy and points towards that procedure is unfavorable in these conditions.[21,23] Parameatal based flap urethroplasty (Mathieu's procedure) is another commonly used standard procedure for the repair of distal penile hypospadias with complication rate of less than $4 \%$ in different series.[24,25] However this repair creates a horizontal and rounded meatus which is commonly less acceptable than normal slit like opening and meatal stenosis is more common in TIP urethroplasty. $16,24,25]$ In order to overcome these problems some authors have reported series in which both techniques of Incised plate and Mathieu's flap repair have been combined to give better results.[26,27] In the present study, $9(18.75 \%)$ patients with narrow urethral width $(<8 \mathrm{~mm})$ a combined repair TIP with Mathieu's flap was done and in only $1(11.11 \%)$ patient postoperative urethrocutaneous fistula developed which later settled with regular dilatations in the follow up. Cosmetic result was excellent and no case of urethral stenosis occurred in these patients. Salem HK et al, has reported an incidence of $6 \%$ of meatal stenosis and $3 \%$ of urethrocutaneous fistula in their study of combined repair on 33 patients and in all cases meatal stenosis responded to regular dilatations and UCF was repaired.[27] El Ganamy EOet al. have also reported an incidence of $2.9 \%$ of urethrocutaneous fistula 
Annals of International Medical and Dental Research

E-ISSN: 2395-2822 | P-ISSN: 2395-2814

Vol-8, Issue-1 | January-February 2022

DOI: 10.53339/aimdr.2022.8.1.20

Page no- 149-158 | Section- Research Article (Paediatric Surgery)

but no meatal stenosis in a series of 34 patients with excellent results. ${ }^{28]}$ In our study we also evaluated the incidence $(28.57 \%)$ of urethrocutaneous fistula in age group more than 10 years and $(12.19 \%)$ in age group less than 10 years. Hirgude ST and Kadale SB have also reported an incidence of $62.5 \%$ in the age group greater than 10 yrs.[29] Dodson J et al., have reported an incidence of urethrocutaneousfisula of $48 \%$ in ages above 10 years as compared to $28.57 \%$ in present study.[29] In our study we also evaluated the role of preoperative androgen therapy in decreasing the complications as has been published by various authors in their series. $[13,14]$ The incidence of major complications i.e UCF was seen in 5 (22.7\%) out of 22 patients in which preoperative testosterone was not given as compared to 2 $(8.33 \%)$ out of 26 patients who received preoperative androgen therapy. Snodgrass $W$ et al.,have also reported that the incidence of complications like glans dehiscence and fistula formation decreases from $13 \%$ to $2.4 \%$ by testosterone therapy.[13] Asgari SA et al., have reported in their study that the incidence of urethrocutaneous fistula was more in 7.69\% patients who were not given preoperative testosterone therapy as compared to $4.39 \%$ where it was given and similarly meatal stenosis was more in $3.29 \%$ patients as compared to $1.09 \%$ patients. [30] Ahmed $\mathrm{R}$ et al.,have reported in their study that preoperative testosterone therapy improves the vascularity of penile skin, increases the size of phallus and improves the surgical outcome of hypospadias repair.[31] We also evaluated the effect of urethral plate width on outcome of hypospadias repair as we performed combined repair in distal penile hypospadias patients with width less than $8 \mathrm{~mm}$ and TIP urethroplasty in patients with a urethral width of more than $8 \mathrm{~mm}$ and complication rate incidence was almost same. However fistula occurred in $4(50 \%)$ patients of mid penile and proximal types with a urethral plate width of greater than $8 \mathrm{~mm}$ which underwent TIP repair which shows that TIP is not an ideal procedure in these circumstances. Some authors have reported higher incidence of complications in cases with urethral width less than $8 \mathrm{~mm}$. Aboutaleb $\mathrm{H}$ reported in a series of 100 patients who had underwent TIP repair that the fistula rate was $23 \%$ in patients with urethral width less than $8 \mathrm{~mm}$ as compared to $2.4 \%$ in patients with urethral plate width greater than $8 \mathrm{~mm}$. [32] Bush NC and Snodgrass $\mathrm{W}$ are of the opinion that urethral plate width does not affect outcome of TIP repair.[15] However in distal group we performed combined repair in narrow uretheral plate width of $<8 \mathrm{~mm}$ which decreased the fistula rate and we recommend this as a preferred procedure for the same. In our study there were also $2(4.16 \%)$ cases of meatal stenosis; one in TIP repair and another in combined repair both of which responded to dilatation in the follow up. The incidence of meatal stenosis reported in other studies is $6-6.5 \%$ which is comparable to the present study. ${ }^{6,27]}$ In follow up all the patients were calibrated with appropriate size feeding tube to access for the meatal stenosis and caliber of neourethra. In 2 patients urethrocutaneous fistula disappeared with regular calibration which has also been reported by others. [6]

\section{CONCLUSIONS}

MAGPI is an ideal technique for glanular and coronal hypospadias with low complication 
Annals of International Medical and Dental Research

E-ISSN: 2395-2822 | P-ISSN: 2395-2814

Vol-8, Issue-1 | January-February 2022

DOI: 10.53339/aimdr.2022.8.1.20

Page no- 149-158 | Section- Research Article (Paediatric Surgery)

rate. TIP should be offered to patients of distal penile hypospadias with wide urethral plate. Combined repair (TIP and Mathieu's) is an excellent procedure in distal penile hypospadias with narrow urethral plate width

\section{REFERENCES}

1. Leung AK, Robson WL. Hypospadias: an update. Asian J Androl. 2007;9(1):16-22. doi: 10.1111/j.17457262.2007.00243.x.

2. Ságodi L, Kiss A, Kiss-Tóth E, Barkai L. A hypospadiasis gyakorisága és lehetséges okai [Prevalence and possible causes of hypospadias]. Orv Hetil. 2014;155(25):978-85. doi: 10.1556/OH.2014.29858.

3. Lepor H. Pathophysiology, epidemiology, and natural history of benign prostatic hyperplasia. Rev Urol. 2004;6 Suppl 9(Suppl 9):S3-S10.

4. AlTaweel WM, Seyam RM. Hypospadias repair during adulthood: Case series. Urol Ann. 2017;9(4):366-371. doi:10.4103/UA.UA_54_17

5. Bhat A. General considerations in hypospadias surgery. Indian J Urol. 2008;24(2):188-194. doi:10.4103/0970-1591.40614

6. Retik AB, Borer JG. Primary and reoperative hypospadias repair with the Snodgrass technique. World J Urol. 1998;16(3):186-91. doi: 10.1007/s003450050050.

7. Rushton HG, Belman AB. The split prepuce in situ onlay hypospadias repair. J Urol. 1998;160(3 Pt 2):1134-6.

8. Elganainy EO, Abdelsalam YM, Gadelmoula MM, Shalaby MM. Combined Mathieu and Snodgrass urethroplasty for hypospadias repair: a prospective randomized study. Int J Urol. 2010;17(7):661-5. doi: 10.1111/j.1442-2042.2010.02537.x.

9. Anwar-ul-haq, Akhter N, Nilofer, Samiullah, Javeria. Comparative study of Mathieu and Snodgrass repair for anterior hypospadias. J Ayub Med Coll Abbottabad. 2006;18(2):50-2.

10. Atici A, Celikkaya ME, EL C, Akcora B. Results of Surgery performed on 151 patients of hypospadias. Single centre Experience. Ulutas Med J. 2019; 5(1): 4853. http://dx.doi.org/10.5455/umj.20181210085830 resulting in good cosmetic appearance and low complications . Complication rate is more in older age group and preoperative androgen therapy decreases the incidence of complications.

11. Yildiz T, Tahtali IN, Ates DC, Keles I, Ilce Z. Age of patient is a risk factor for urethrocutaneous fistula in hypospadias surgery. J Pediatr Urol. 2013;9(6 Pt A):900-3. doi: 10.1016/j.jpurol.2012.12.007.

12. da Silva EA, Lobountchenko T, Marun MN, Rondon A, Damião R. Role of penile biometric characteristics on surgical outcome of hypospadias repair. Pediatr Surg Int. 2014;30(3):339-44. doi: 10.1007/s00383-0133442-1.

13. Snodgrass W, Macedo A, Hoebeke P, Mouriquand PD. Hypospadias dilemmas: a round table. J Pediatr Urol. 2011;7(2):145-57. doi: 10.1016/j.jpurol.2010.11.009.

14. Wright I, Cole E, Farrokhyar F, Pemberton J, Lorenzo AJ, Braga LH. Effect of preoperative hormonal stimulation on postoperative complication rates after proximal hypospadias repair: a systematic review. J Urol. 2013;190(2):652-59. doi: 10.1016/j.juro.2013.02.3234.

15. Bush NC, Snodgrass W. Pre-incision urethral plate width does not impact short-term Tubularized Incised Plate urethroplasty outcomes. J Pediatr Urol. 2017;13(6):625.e1-625.e6.

doi: 10.1016/j.jpurol.2017.05.020.

16. Holland AJ, Smith GH. Effect of the depth and width of the urethral plate on tubularized incised plate urethroplasty. J Urol. 2000;164(2):489-91.

17. Duckett JW, Snyder HM 3rd. The MAGPI hypospadias repair in 1111 patients. Ann Surg. 1991;213(6):620-626. doi:10.1097/00000658-19910600000012

18. Mohammed WM, Davis NF, O'Connor KM, Kiely EA. Re-evaluating the role of Doppler ultrasonography in patients presenting with scrotal pain. Ir J Med Sci. 2016;185(3):705-709. doi: 10.1007/s11845-015-1349-7.

19. Snodgrass W. Tubularized, incised plate urethroplasty for distal hypospadias. J Urol. 1994;151(2):464-5. doi: 10.1016/s0022-5347(17)349911. 
Annals of International Medical and Dental Research

E-ISSN: 2395-2822 | P-ISSN: 2395-2814

Vol-8, Issue-1 | January-February 2022

DOI: 10.53339/aimdr.2022.8.1.20

Page no- 149-158 | Section- Research Article (Paediatric Surgery)

20. Steven L, Cherian A, Yankovic F, Mathur A, Kulkarni M, Cuckow P. Current practice in paediatric hypospadias surgery; a specialist survey. J Pediatr $\begin{array}{llll}\text { Urol. } \quad 2013 ; 9(6 & \mathrm{Pt} & \text { B):1126-30. doi: }\end{array}$ 10.1016/j.jpurol.2013.04.008.

21. Pfistermuller KL, McArdle AJ, Cuckow PM. Metaanalysis of complication rates of the tubularized incised plate (TIP) repair. J Pediatr Urol. 2015;11(2):54-9. doi: 10.1016/j.jpurol.2014.12.006.

22. Braga LH, Lorenzo AJ, Salle JL. Tubularized incised plate urethroplasty for distal hypospadias: A literature review. Indian J Urol. 2008;24(2):219-225. doi:10.4103/0970-1591.40619

23. Ahmad K. Snodgrass repair for distal hypospadias: a review of 75 cases. Ann PedSurg. 2012; 8: 12-14.

24. Oswald J, Körner I, Riccabona M. Comparison of the perimeatal-based flap (Mathieu) and the tubularized incised-plate urethroplasty (Snodgrass) in primary distal hypospadias. BJU Int. 2000;85(6):725-7. doi: 10.1046/j.1464-410x.2000.00479.x.

25. Yesildag E, Tekant G, Sarimurat N, Buyukunal SN. Do patch procedures prevent complications of the Mathieu technique? J Urol. 2004;171(6 Pt 2):2623-5. doi: 10.1097/01.ju.0000112781.93314.f3.

26. Nilamani $M$, Bhusan NB, Annadaprasad P. Combined Use of the Mathieu and Incised Urethral Plate Techniques for Repair of Distal Penile Hypospadias. Indian J Surg. 2015;77(Suppl 2):694697. doi:10.1007/s12262-013-0988-z
27. Salem HK, Shelbaia A, Elnashar A. Combined use of Mathieu and incised plate technique (Snodgrass technique) for repair of distal hypospadias in older children. African Jr of Urology. 2013;19;74-77.

28. Viseshsindh W. Factors affecting results of hypospadias repair: single technique and surgeon. J Med Assoc Thai. 2014;97(7):694-8.

29. Dodson JL, Baird AD, Baker LA, Docimo SG, Mathews RI. Outcomes of delayed hypospadias repair: implications for decision making. J Urol. 2007;178(1):278-81. doi: 10.1016/j.juro.2007.03.055.

30. Asgari SA, Safarinejad MR, Poorreza F, Asl AS, Ghanaie MM, Shahab E. The effect of parenteral testosterone administration prior to hypospadias surgery: A prospective, randomized and controlled study. J Pediatr Urol. 2015;11(3):143.e1-6. doi: 10.1016/j.jpurol.2014.12.014.

31. Ahmad R, Chana RS, Ali SM, Khan S. Role of parenteral testosterone in hypospadias: A study from a teaching hospital in India. Urol Ann. 2011;3(3):13840. doi: 10.4103/0974-7796.84966.

32. Aboutaleb $\mathrm{H}$. Role of the urethral plate characters in the success of tubularized incised plate urethroplasty. Indian J Plast Surg. 2014;47(2):227-31. doi: 10.4103/0970-0358.138956.

Source of Support: Nil, Conflict of Interest: None declared 